\title{
The Influence of Fiscal and Financial Policies on Upgrading of Regional Industrial Structure
}

\author{
Jing Chen \\ School of Development Economics, National Institute of Development Administration, Bangkok, Thailand \\ Email: Lemonch-jing@163.com
}

How to cite this paper: Chen, J. (2021) The Influence of Fiscal and Financial Policies on Upgrading of Regional Industrial Structure. Open Access Library Journal, 8: e7648. https://doi.org/10.4236/oalib.1107648

Received: June 15, 2021

Accepted: November 21, 2021

Published: November 24, 2021

Copyright $\odot 2021$ by author(s) and Open Access Library Inc.

This work is licensed under the Creative Commons Attribution International License (CC BY 4.0).

http://creativecommons.org/licenses/by/4.0/

\begin{abstract}
Policies to encourage economic development are different in different regions. Studies at home and abroad show that the financial development level and local GDP output value are relatively high in places with a high proportion of tertiary industry such as financial agglomeration and high-tech development level, and vice versa. The upgrading of industrial structure is an important part of China's supply-side structural reform, and also a necessary measure to promote regional economic development. Upgrading of industrial structure needs to have a stable macroeconomic environment, more in need of financial means of guidance, the appropriate fiscal and monetary policy can be formulated and implemented a variety of effective tools to infiltrate into the whole process of industrial development, induced flow of each factor, the backward industry, optimize the configuration of the relationship between the elements in different industries, so as to realize transformation of industrial structure upgrade. Thus it can be seen that whether the fiscal and financial policies are guided in place, whether there are gaps and deficiencies, has a very important practical role in the adjustment of China's industrial structure. This paper clarifies the relationship between fiscal and financial development and regional industrial structure on the basis of the research results of policy-based finance supporting industrial structure transformation at home and abroad and makes an in-depth study of the impact of some regional fiscal and financial policies on the upgrading of industrial structure, so as to provide valuable references and suggestions for realizing the coordinated development of regional economy.
\end{abstract}

\section{Subject Areas}

Development Economics 


\section{Keywords}

Fiscal and Financial Policy, Regional Industrial Structure, Upgrade, Influence

\section{Introduction}

\subsection{Objective}

Reform and opening-up have made China's economy develop rapidly and become the second-largest economy in the world. However, behind the rapid development, with the intensification of global economic competition, China's economic growth model is also changing. The dominant industry of economic growth is shifting from labor-intensive industries to capital and technology-intensive industries, and the industrial structure is also upgrading to high-tech, high value-added and high service industries. Due to the influence of the economic development mode and the lagging economic reform, China's industrial development faces serious structural problems. The increasing constraints on resources and the environment and the rising costs of production factors are still hindering China's economic development. Under the new normal, China's economy will do better, achieving high-quality development, inevitably puts forward new requirements to the industrial structure upgrade, so to promote the supply-side structural reform one of the important tasks of the industrial structure upgrade, has become a significant innovation to adapt to and lead the economic development of the new normal, promoting the old and new momentum in the important place gripper and fill shortboard, improve the breakthrough to the consumer. However, promoting the upgrading of the industrial structure needs a certain external environment and objective conditions, which cannot be separated from the support and coordinated development of the financial industry [1]. As the core of the modern economy, finance carries the capital input for economic development and is an important driving force to promote economic transformation and upgrading and sustained growth under the new normal. At the same time, with the deepening of fiscal and financial marketization reform, the unbalanced allocation of resources is obvious. Resource agglomeration has become an important trend of modern financial development, while strong fiscal and financial policies are the support to realize the upgrading of industrial structure. Therefore, this article explores fiscal and monetary policy impact on industrial structure upgrade, not only to comply with the concept of financial services in the real economy development, and meet the objective demand of the new normal industrial structure upgrade, to promote the sustainable development of regional economy and the quality of our country economy development has important theoretical significance and practical significance [2].

\subsection{Framework}

Figure 1 shows the overall framework of the paper and explains the content of 
the paper in a simple and clear way. From the abstract, domestic and foreign research, argumentation, problems and solutions. This paper expounds on the influence of financial policy on industrial upgrading. This is the theme of the article, and it is also the biggest change in society today.

\subsection{Hypothesis}

Hypothesis: The upgrading of industrial structure is relatively fast in economically developed areas that would lead local GDP higher.

From Table 1, we can know that the three big industry ratios, thus can calculate the change rate of the ratio of the second and the third industry regions (Table 2).

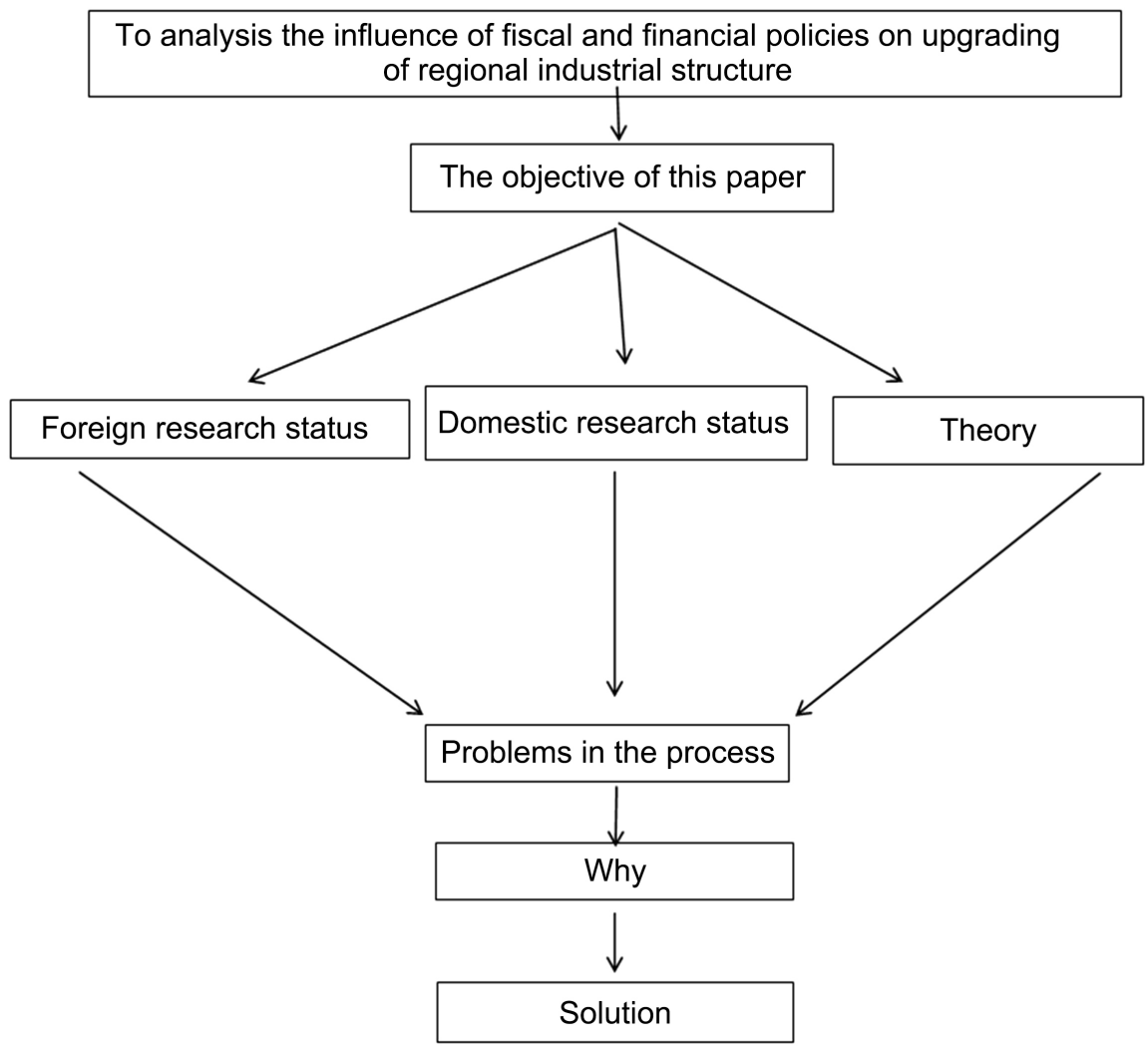

Figure 1. Framework of this paper.

Table 1. Ratio of three industries from 2016-2020.

\begin{tabular}{ccccccc}
\hline & Henan & Shanxi & Hunan & Guangdong & Zhejiang & Jiangsu \\
\hline 2016 & $10: 47: 43$ & $6: 43: 51$ & $9: 42: 49$ & $4: 43: 53$ & $4: 46: 50$ & $5: 45: 50$ \\
2017 & $9: 47: 44$ & $5: 46: 49$ & $9: 40: 51$ & $4: 42: 54$ & $4: 44: 52$ & $5: 46: 49$ \\
2018 & $8: 44: 48$ & $5: 44: 51$ & $8: 38: 54$ & $4: 41: 55$ & $3: 44: 53$ & $4: 45: 51$ \\
2019 & $8: 43: 49$ & $5: 44: 51$ & $9: 38: 53$ & $4: 40: 56$ & $3: 42: 55$ & $4: 44: 52$ \\
2020 & $10: 41: 49$ & $5: 43: 52$ & $10: 38: 52$ & $4: 39: 57$ & $3: 41: 56$ & $4: 43: 53$ \\
\hline
\end{tabular}


Table 2. The change ratio of the second and third industry regions 2016-2020.

\begin{tabular}{ccccccc}
\hline & Henan & Shanxi & Hunan & Guangdong & Zhejiang & Jiangsu \\
\hline 2017 & 0.011 & 0.010 & 0 & 0 & 0 & 0 \\
2018 & 0.010 & 0 & 0.010 & 0 & 0.010 & 0.010 \\
2019 & 0 & 0 & -0.010 & 0 & 0 & 0 \\
2020 & -0.032 & 0 & -0.010 & 0 & 0 & 0 \\
\hline
\end{tabular}

From the calculation, we can see that the developed region of the mean value is positive, negative the average of the developed areas. So can conclude that the industrial structure upgrade is positively related to the impact on the local GDP. So fast growth.

Because financial aggregation can make business integration, information dissemination, labor specialization and other advantages of scale economy, reduce transaction costs, improve the circulation capacity of capital, alleviate the capital constraints of industrial structure upgrading.

In economically developed areas such as Shanghai and Guangdong, which are dominated by the high service industry and high value-added industry, local GDP growth is fast and there is enough fiscal expenditure to support the upgrading of industrial structure. Compared with the backward regions, such as the central and western regions, it is mainly based on the first and second traditional industries, and the industrial structure development is relatively slow. Economic structure and economic development level structure lead to different levels of industrial upgrading and structural change in different regions.

\section{Theoretical Research on the Impact of Fiscal and Financial Policies on Industrial Structure Upgrading}

\subsection{Foreign Research Results}

The theory of industrial structure comes from the Political Arithmetic written by William Petty, a British economist in the 17th century. In this book, he pointed out that manufacturing industry can get more income than agriculture, and then commerce can get more income than manufacturing industry. The difference in relative income leads to the concentration of labor force to industry and commerce. Colin Clark, on the basis of the match in the first development, formed the match first Clark theorem, the theorem is pointed out that the trend of the industrial structure of the second and third industry relative to the first industry in local GDP proportion increase gradually, the industrial structure rationalization is the dominant orderly succession of leading industries, the tertiary industry accounted for the final will be more than the second industry. When Goldsmith established the theory of financial development, he proposed the classic FIR index in his article Financial Structure and Financial Development, which verified the positive correlation between the level of economic develop- 
ment, the advancement of industrial structure and financial development [3]. Goldsmith, an American economist, published his book Financial Structure and Financial Development in 1969. Goldsmith believed that financial development is manifested by diversification of financial assets and diversification of financial intermediaries. The process of financial development promotes the formation of savings and investment and improves the efficiency of investment. Finance is a powerful means to optimize the allocation of resources and adjust the structure in economic growth. Rajan and Zingales (1998) explored the mechanism of financial development on industrial structure upgrading by examining the relationship between financial development level and industrial growth level of a country. The research results showed that financial development can effectively reduce the financing cost of enterprises and help the development and growth of emerging enterprises from the capital level, thus improving the efficiency of capital allocation, and indirectly promoting the upgrading of the industrial structure of a country. From the perspective of finance and investment, Wurgler (2000) found that a country with a more developed financial market has a higher efficiency in resource allocation. Finance can enable more resources to be invested in emerging industries, thus promoting industrial upgrading. The research of Fishman\&Love (2007) shows that financial development selectively promotes the rapid development of some competitive industries. In terms of the relationship between financial development and economic growth, there has been a lot of discussion in international academia for a long time. Shaw and Gurley (1955), Patrick (1966), Goldsmith (1969), Aghion and Howitt (2009) and other studies support the view that financial development can promote economic growth. Park and Essayyad (1989) believe that financial agglomeration plays a special role in the process of industrial structure upgrading: financial agglomeration enables financial institutions to gain advantages of scale economy in business cooperation, information dissemination, labor specialization and facility sharing, etc. and reduces transaction costs. Kindleberger (1974) believed that it improved the circulation capacity and allocation efficiency of capital and eased the capital constraint of industrial structure upgrading [4].

\subsection{Domestic Research Status}

The theory of regional finance, which began in the 1990s, is a new research field-initiated and promoted by Chinese scholars, and the relationship between fiscal and financial policies and the upgrading of regional industrial structure is one of the focuses of the study of regional finance theory. Fan Fangzhi and Zhang Lijun (2003) found in the study of the eastern, central and western regions of China that the transformation of financial structure can promote the upgrading of industrial structure, especially the slow industrial upgrading in the central region impedes financial development, and the lag of financial structure transformation also delays the upgrading of industrial structure. Zhi Dalin and Zhu Xiaobo (2004) put forward the theoretical model of the influence of regional 
financial development on regional industrial structure change under the condition of opening up. Ye Yaoming and Ji Cuiling (2004) took the Yangtze River Delta urban agglomeration as the research object and concluded that the financial development of the Yangtze River Delta urban agglomeration could effectively promote the upgrading of the industrial structure of the region [5]. Based on previous studies, Liu Ganzhou (2005) took the central region as an example to analyze the positive impact of financial support on the upgrading of industrial structure. Hui Xiaofeng and Shen Jing (2006) took the three northeastern provinces as the research object and used multiple regression analysis to empirically analyze the relationship between financial development and industrial structure upgrading in the three northeastern provinces, and concluded that financial development in the three northeastern provinces had a certain influence on industrial structure upgrading. Ma Chili and Zhou Xiangyu (2008) used non-stationary time series analysis to empirically analyze the relationship between China's financial development and industrial structure upgrading from 1978 to 2006, and concluded that there was only a one-way causal relationship between financial development and industrial structure upgrading, that is, financial development drove the optimization and upgrading of industrial structure, but the reverse was not true. Zhang Xu, Wu Haihua (2001), Yang Lin, Li Jianwei (2002), Ge Hongling (2009) and He Xiaoxia (2011) made theoretical analysis on the transmission mechanism and path of the impact of financial development on industrial structure and believed that financial deepening is conducive to the optimization and upgrading of industrial structure. Li Pinghai and Wang Xue (2009) investigated the upgrading of industrial structure in Guangdong Province from the perspective of financial agglomeration and found that financial agglomeration supported the upgrading of the industrial structure by broadening financing channels and improving the efficiency of capital supply and allocation. From the perspective of industry heterogeneity, Sun Jing and Li Hanshuo (2012) investigated the impact of financial segmentation industry agglomeration on the upgrading of industrial structure and found that financial agglomeration has a significant promoting effect on the upgrading of industrial structure, but it is mainly reflected in the radiation effect of the banking industry, while the promoting effect of securities industry and insurance industry is limited. He Haixia (2013) took Henan Province as an example to study and believed that the financial scale of Henan Province did not promote the upgrading of industrial structure, but inhibited it. Yang Yiwu and Fang Dachun (2013) point out that the impact of financial agglomeration on economic growth is mainly realized through the upgrading of industrial structure. Qiu Wei (2014) established the VAR model and found that direct financing and indirect financing could promote the upgrading of industrial structure in Hunan Province. According to the Granger causality test, indirect financing is the reason for the upgrading of industrial structure, but industrial structure upgrading is not the reason for indirect financing. Zhu Yujie and Ni Xiaoran (2014) pointed out in their research 
that the direct and indirect effects of financial agglomeration in eastern and central regions did not promote industrial upgrading, but significantly promoted industrial upgrading in western regions. Li Yuze and Chen Tao (2014) made use of the panel data of two provinces and one city in the Yangtze River Delta and tested them by OLS and fixed effect methods respectively, and found that government intervention and scientific and technological activities had a positive effect on the upgrading of industrial structure in the Yangtze River Delta, while financial factors inhibited the upgrading of industrial structure. Wang Dan and Ye Shujun (2015) believe that financial agglomeration improves the total amount of knowledge and technology and the average level of cognition in the region through the knowledge spillover effect, effectively promotes the improvement of the level of regional technological innovation and lays a technological foundation for the upgrading of industrial structure. Jing Guowen (2016) used the panel data of prefecture-level cities in Shanxi Province to study the relationship between financial scale and financial correlation ratio and industrial structure upgrading. By adding infrastructure, government intervention, urbanization level and economic openness as control variables, he found that both financial scale and financial correlation ratio could promote industrial structure upgrading. Referring to the research framework of new economic geography, $\mathrm{Yu}$ Binbin (2017), Liu Pei and Li Qi (2014) examined the spatial spillover effect of financial agglomeration on industrial structure upgrading and found that financial agglomeration can not only promote the upgrading of local industrial structure but also serve the upgrading of industrial structure in neighboring or other regions in a long distance and in a wider range [6].

\subsection{Methodology: Regression and Theory}

$$
y=\beta_{0}+\beta_{i} * X_{i}+\varepsilon_{i}
$$

In this equation, $\varepsilon_{i}$ is random errorterm. $y$ is a dependent variable. $X$ can be independent variable.

Here, $y=$ local GDP.

$X=$ the ratio of three industries in different provinces.

Let's use regression analysis to make a statistical analysis based on the two variables and analyze the impact of industrial structure on local GDP by using the positive correlation between the ratio of the three major industries and the local GDP output value. Therefore, according to the data in Table 1 and Table 3, we know that.

According to the regression analysis, we substituted the data of different provinces and analyzed the impact of different fiscal and financial policies on industrial upgrading according to the proportion of the three industries in local GDP in different provinces in China, for example, Henan, Shanxi, Hunan, Guangzhou, Zhejiang, Jiangsu and so on. These provinces are located in the east, west, central and south. The level of financial development is completely different, so it is the industrial structure. This leads to the following data (Table 4). 
Table 3. Local GDP from 2016-2020 (units: one hundred million yuan).

\begin{tabular}{cccccccc}
\hline & Henan & Shanxi & Hunan & Guangdong & Zhejiang & Jiangsu \\
\hline 2016 & $40,249.3$ & $11,946.4$ & $30,853.5$ & $82,163.2$ & 47,254 & $77,350.9$ \\
2017 & $44,824.9$ & $14,484.3$ & $33,828.1$ & $91,648.7$ & $52,403.1$ & $85,869.8$ \\
2018 & $49,935.9$ & $15,958.1$ & $36,329.7$ & $99,945.2$ & $58,002.8$ & $93,207.6$ \\
2019 & $53,717.8$ & $16,961.6$ & $39,894.1$ & $107,986.9$ & 62,462 & $98,656.8$ \\
2020 & $54,997.1$ & $17,651.9$ & $41,781.5$ & $110,760.9$ & $64,613.3$ & 102,719 \\
\hline
\end{tabular}

Notes: All the data is from national bureau of statistics.

Table 4. Result data.

\begin{tabular}{ccccccc}
\hline & Multiple R & R Square & $\begin{array}{c}\text { Adjusted R } \\
\text { Square }\end{array}$ & $\begin{array}{c}\text { Standard } \\
\text { error }\end{array}$ & Significance F & F \\
\hline Henan & 0.378633 & 0.143363 & -0.142182877 & 6604.97 & 0.52969 & 0.502066 \\
Shanxi & 0.870794 & 0.758283 & 0.677710551 & 1287.921 & 0.0546581 & 9.411204 \\
Hunan & 0.39803 & 0.158428 & -0.122096279 & 4691.419 & 0.50693166 & 0.564756 \\
Guangdong & 0.98594 & 0.972078 & 0.962770153 & 2275.365 & 0.00199708 & 104.4407 \\
Zhejiang & 0.922774 & 0.851511 & 0.802015267 & 3184.64 & 0.02546157 & 17.20358 \\
Jiangsu & 0.898695 & 0.807652 & 0.743535931 & 5138.878 & 0.03811281 & 12.59673 \\
\hline
\end{tabular}

Notes: All the date is worked out by form excel sheet.

To sum up, there is a positive correlation between financial development and industrial structure upgrading at present, and the level of financial development is conducive to industrial structure transformation and upgrading. How to further study the influence of financial development of province, city and county on the upgrading of regional industrial structure at the regional level will be one of the core issues of regional financial research. Based on the research of existing scholars, this paper studies the influence of fiscal and financial development on the upgrading of industrial structure in some regions, aiming to explore the influence of fiscal and financial development on the upgrading of regional industrial structure and enrich the research in this field. It provides reference for the formulation of inter-regional fiscal and financial policies [7].

\section{Problems Existing in the Process of Promoting the Upgrading of Industrial Structure through Finance and Finance}

On the basis of the existing research on financial development and industrial structure upgrading, and based on the provincial data of representative regions in the east, central and west, such as the balance of deposits and loans, premium income and urban population published in the official website, China Financial 
Yearbook and China Statistical Yearbook, this paper adopts the panel data model. On the basis of controlling the variables of foreign direct investment, final consumption and regional economic development level, this paper makes an in-depth study on the influence of financial development in the eastern, central and western regions on the upgrading of their industrial structure, and finds the following problems in the promotion of regional industrial structure by fiscal and financial policies:

1) Financial policies still focus on heavy structure and ignore the coordinated and healthy development of the tertiary industry. Financial policy is an important thrust to promote transformation and upgrading of the industrial structure, strengthen the support of the third industry in our country in recent years, but in terms of demand for the development of the third industry present situation, fiscal and financial policy support for the third industry is larger defects, especially for the development of small and mid-sized enterprise support there is a big gap, according to the incomplete survey, China's small and micro science and technology enterprises financing gap is very large, affecting the healthy development of China's science and technology industry [8].

2) China's capital market is not perfect, affecting the adjustment of industrial structure. The healthy development of the capital market to promote the adjustment of industrial structure has an important significance in promoting, but the development of the capital market in China still exist many problems, especially the capital market mechanism is imperfect seriously affect the transform and upgrade the industrial structure, in the case of the small and medium-sized third board, because the platform exists many defects, cause the enterprise to use the platform of efficiency is not high.

3) The pulling effect on various industries is not balanced. As profit-making institutions, commercial financial institutions, especially commercial banks, invest more in the tertiary industry with higher added value and give less support to the primary and secondary industries. In this context, the support to the primary and secondary industries is more dependent on the injection of policy-based finance funds.

4) There are differences in pulling effect between regions. After a long period of development, infrastructure services in relatively backward areas have been gradually improved, coupled with the tilt of national policy funds, promoting the obvious impact of finance on the upgrading of industrial structure in this region. Under the attack of the prosperity of the east and the development of the west and the lack of national policy, the central region lags behind in opening up, the economic growth is lower than that of the west, and the ability of financial allocation of resources is weak, which leads to the insignificant effect of financial development on the upgrading of industrial structure in the central region.

\section{Cause Analysis}

1) Imbalanced regional economic development. The influence of financial de- 
velopment on the upgrading of industrial structure in the eastern, central and western regions of China shows significant regional differences, and the regional financial development in the eastern and western regions plays a positive role in promoting the optimization and upgrading of industrial structure. However, in the central region, regional financial development has a negative effect on the optimization and upgrading of industrial structure. China Eastern, central and western regional differences in financial development and industrial structure upgrade existing reasons might be since the reform and opening up national policy tilt and location advantage to make the eastern region to lead the country in development and marketization degree, economic development level, attracting foreign investment, resources advantage, prompting financial ACTS on the channels of the industrial structure. The central and western regions show a decreasing trend.

2) The influence mechanism of fiscal policy on industrial structure upgrading. It is mainly reflected in two aspects, one is the influence mechanism of tax policy. Tax revenue is the country to meet the needs of the society, and through the law, administrative means to achieve the average distribution of social wealth. Tax policy can control and regulate national income by concentrating income, thus affecting the change of industrial structure. The second is the influence mechanism of fiscal expenditure policy [9]. Fiscal expenditure is oriented to the adjustment of industrial structure through the allocation of fiscal expenditure. Classifying according to the nature of economy, fiscal expenditure covers the purchasing nature and the transfer nature. Purchasing nature refers to the impact on employment and production achieved through the government's purchase of social products. Transferability means that the government transfers financial funds free of charge to realize the adjustment and upgrading of industrial structure and the role of fiscal expenditure policies is not perfect, resulting in the impact of industrial structure upgrading.

3) The impact of monetary policy. Considering the differences in the level of regional financial development and the upgrading degree of industrial structure in China, the implementation of unified monetary policy tools by the central bank is often not conducive to the optimization and upgrading of industrial structure and the coordinated development of regional economy in underdeveloped areas. When the rate of return on capital is relatively high in the eastern region, the central bank implements unified monetary policy tools, which obviously affects the development of financial activities in the less developed regions, leads to a large number of continuous outflow of savings deposits in the central and western regions, and widens the gap of regional financial development level.

\section{The Impact of Fiscal and Financial Policies on the Upgrading of Industrial Structure}

1) Improve fiscal tax policies and promote the upgrading of industrial struc- 
ture. Fiscal tax plays a guiding role in the realization of industrial structure adjustment and upgrading, so the government departments should actively implement the strategic objectives of industrial structure upgrading: First, to further promote and implement the VAT reform. VAT reform is our country building economy embodies the new normal, promoting the reform of the supply side, through the value-added tax reform can be implemented to the industrial structure upgrade guide, a change of policy orientation camp, more emphasis on promoting service industry especially the development of producer services, such as research and development, promote the optimization of the industrial division, lengthen industrial chain, upgrading manufacturing. Second, we will improve the types of taxes. The Chinese government should constantly optimize the tax burden and tax types in the upgrading and transformation of industrial structure and realize the upgrading of industrial structure through the perfect tax types. Third, speed up the development of the service industry in central China and promote the balanced development of the tertiary industry. Due to the reasons of the early national policies, coupled with the lack of development power in the central region itself, the central region is inferior to the eastern region in terms of economic aggregate, inferior to the western region in terms of development speed, and the industrial structure changes lag behind the situation. In promoting the development of service industry, the tax policy should adjust measures to local conditions, follow the economic developed area does not advocate the industry to improve the restricted measures such as tax rate, reduce the deduction, weak areas of tax on economic growth, encouraging measures, such as accelerated depreciation in tax policy and at the same time, in use process should pay attention to the fairness of the tax technology, professional, convenience [10].

2) Optimize financial policy tools and promote the optimization of industrial institutions. First, increase credit input and optimize the structure of financial institutions. Financial institutions should increase their support for small and medium-sized enterprises, especially the technology industry, so as to realize the guiding function of financial policies. Therefore, financial institutions should adjust the industrial structure through deposit reserve ratio and differential interest rate. At the same time, financial supervision departments should also improve the financial market mechanism by optimizing policies, give full play to the market competition mechanism, vigorously develop foreign banks, and form a diversified financial system. Second, the establishment of multi-level capital market improves the ability to promote the upgrading of industrial structure. China should actively promote the financing capacity of the capital market, and make full use of the main board market, entrepreneurial market and other platforms to promote the development of the third new industry. For example, venture capital can be introduced to high-tech industries to realize the development of high-tech industries. The third is to guide the flow of credit and inject the central bank's base money into the lending behavior of commercial banks more 
closely, so as to enhance the financial support for the key and weak links in economic development.

3) Improve financial efficiency and further improve the financial system. Financial development is not only the expansion of financial scale, but more importantly the improvement of financial efficiency. At present, China's financial system is still mainly dominated by the banking industry. Bank credit is the main way of financing for Chinese enterprises. The rapid development of small and medium-sized banks promotes the development of the real economy. However, the development level of China's capital market is still relatively backward, the level of direct financing is low, the risk investment market is not perfect, and the financial supervision is not enough, which hinders the financing demand of some industries. Therefore, it is necessary to establish and improve the financial market, improve the financial efficiency, and give play to the role of the financial system in promoting the transformation and upgrading of industrial structure. At the same time, attention should be paid to stimulating the vitality of talents and improving the quality of human resources. Human resources are an important factor to promote regional economic development, scientific and technological progress and enterprise transformation. This paper finds that the improvement of human capital level in developed regions has no significant effect on promoting industrial structure transformation and upgrading. Human resources as the main driving force of economic development, not only needs the local government to actively implement the talent introduction policy, establish a good talent incentive mechanism, and improve the talent growth path. In addition, it is necessary to innovate the talent training mechanism, fully tap the ability of all kinds of talents, and improve the comprehensive quality and quality of human resources [11].

4) Innovate technological financial products. First, banks should be encouraged to innovate financial instruments to provide more diversified financial products. We will also promote direct financing and encourage high-tech enterprises to issue bonds to borrow funds and expand the scale of their funds. Second, we will study mechanisms for guaranteeing science and technology. Exploring effective guarantee methods and establishing special fund for science and technology guarantee, the government and guarantee institutions can also bear the risk of loss when serving science and technology enterprises, so as to promote the guarantee market to contribute to the development of science and technology finance. Third, we will improve the system for investment operation. This performance in the sound investment of the relevant policies and legal provisions guide enterprises in the GEM financing. It is also necessary to improve the withdrawal mechanism of funds, promote the reinvestment of withdrawn funds, accelerate capital turnover, and accelerate the growth of innovative enterprises. Fourth, we will formulate differentiated technology and finance policies. In economically developed areas, we will continue to expand the financial market and actively introduce private capital. Preferential policies should be im- 
plemented for investment in science, technology and finance in economically backward areas, such as providing preferential and low-interest loans. Fifth, we will develop blockchain technology to boost science and technology finance. We should vigorously develop blockchain finance, promote the development of science and technology finance, promote the upgrading of industrial structure, and build more intelligent and efficient developed provinces and cities. Sixth, we will train high-quality scientific, technological and financial personnel. On the basis of vigorously introducing domestic and foreign sci-tech and financial talents, Colleges and universities of all kinds should also focus on training more outstanding scientific, technological and financial talents.

5) Adjust the credit structure and optimize the investment of funds. First, credit supports the upgrading of the internal structure of the secondary industry. We will guide the investment of capital in high-tech enterprises and increase the proportion of high-tech industries in the secondary industry. Second, we will focus on supporting the development of modern service industries. We will accelerate the concentration of credit funds in the modern service industry, support the development of emerging industries such as science and technology, logistics, consulting, culture and sports, and education, increase their share in regional GDP, and promote the optimization and upgrading of the service industry structure. Third, we will increase credit support for small and medium-sized enterprises. Develop new financial institutions such as village and town banks, small loan companies and rural mutual fund societies. Local legal person banking should focus on small and medium-sized enterprises and strengthen credit support for local small and medium-sized enterprises. Encouraging commercial banks to innovate and improve such as accounts receivable, intangible assets, export orders, warehouse receipts and other pledge loans and export order financing and other credit products to meet the financing needs of different types of small and medium-sized enterprises; We will increase local financial support, provide support in guarantee and loan risk compensation, and improve the credit investment environment for small and medium-sized enterprises.

6) Establish and improve the regional venture capital system. First, expand the scale of venture capital. We will set up a government guide fund; increase a certain amount of special government funds each year to replenish the government guide fund at the corresponding level, and increase the proportion of government expenditures year by year. Encourage insurance companies, securities companies, listed companies and large non-listed enterprises to establish or share venture capital enterprises; Pilot issuance of venture capital funds to attract wealthy individual capital; We will introduce overseas capital and set up venture capital funds for Sino-foreign joint ventures and cooperative ventures. The second is the establishment of limited partnership system of venture capital enterprises. Limited partnership is the main form of international venture capital enterprises, which has the advantages of efficient incentive and restraint mechanism, tax evasion, unlimited profit distribution and so on. Therefore, when 
the new venture capital institutions, the limited partnership is its first choice. Third, build an information service platform. Relevant departments should set up venture capital information network as soon as possible, establish venture capital service center, lead the establishment of venture capital industry alliance, regularly hold venture capital and venture capital matchmaking meeting and venture capital forum, etc., to serve venture capital investors and venture enterprises. Fourth, we will vigorously train talent for venture capital investment. Implementing the talent strategy of "going out and bringing in" to cultivate venture capital talents; Attract entrepreneurs, experts with rich successful experience and talents with technical background and practical experience to engage in venture capital; Finance and economics institutions of higher learning set up venture capital specialty to cultivate the backup force of venture capital industry. Fifth, we will encourage high-quality enterprises to go public for financing. Relevant departments should make overall planning and set rolling targets for the number of newly listed companies and the amount of financing; we will encourage share-holding reform, mergers and acquisitions and reorganizations, and increase the number and scale of share-holding enterprises. Select a group of enterprises with good growth, independent intellectual property rights and qualified for listing as cultivation objects, and provide guidance and services for restructuring and listing. Sixth, we will accelerate the development of regional over-the-counter markets. The counter market should be established, the property rights trading market should be improved, the direct financing channels of the unlisted enterprises within the jurisdiction should be broadened, and the equity circulation of the unlisted companies should be increased, so as to provide a reasonable way for the venture capital institutions to successfully withdraw from the investee enterprises. Seventh, we will actively develop the corporate bond market. We will increase the size of bond issuance and actively develop corporate bonds, corporate bonds, short-term financing bonds and other debt financing instruments [12].

7) We will vigorously develop financial leasing. The first is the establishment of financial leasing companies. Banks are encouraged to act as major investors and set up financial leasing companies of brand names together with other investors to increase the effective supply in the leasing market. The second is policy support. Vigilously publicize financial leasing, deepen the understanding of all sectors of society on financial leasing, and guide enterprises to establish the leasing concept of "all is not important, and use creates value". Provide supporting policies in taxation, insurance, financing and other aspects to leasing institutions; Encourage some infrastructure projects or key government construction projects to use financial leasing. Third, we will strengthen risk management of financial leasing. A financial leasing company shall establish a risk monitoring and early warning system, conduct regular field visits to the lessee's operating conditions, and analyze the lessee's financial statements and operating conditions. Establish a risk remedy system, including insurance of leased property, collection of lease security, lessee's compensation for breach of contract, guar- 
antee for recovery of the total cost of leased equipment and leased project, etc. The fourth is the construction of financial leasing talent team. Commercial banks have abundant advantages in professional talents, from which the main investors can select talents to enrich the leasing management team; Attract technical experts from related industries to enter the financial leasing industry, specializing in leasing equipment technical management.

8) We will increase policy-based financial support for the central and western regions. First, we will give full play to the guiding role of policy-based finance and promote capital support for industries in "strong positions and weak positions". The transformation and upgrading of industrial structure is an important part of economic new normal and supply-side structural reform. Although high-tech enterprises have better development prospects and strong added value, there are also strong risks in investment. Commercial financial institutions will be restricted by liquidity regulatory indicators and non-performing loan ratio, and their support for high-tech industry is obviously insufficient. Therefore, on the one hand, policy-based finance needs to play the role of "scout" and support the development of high-tech industry through capital injection. On the other hand, it is necessary to play a guiding role in reducing the loan risks of commercial banks and guiding the operation of private capital, so as to play a role in the allocation and regulation of capital, and further optimize and adjust the industrial structure through direct investment and guided investment. Second, we will increase policy-based financial support for the central and western regions to make up for the lack of efficiency in the use of funds and promote coordinated development among regions. Coordinated development and sustainable development are the internal requirements of the new normal of economy, and also the internal requirements of the supply-side structural reform. Especially in the context of poverty alleviation, policy-based finance plays a pivotal role. For example, geographical disadvantages determine that central and western regions need strong support from policy-based finance. From the study of this paper, it can be seen that policy-based finance has a better effect in supporting industrial structure transformation in central and western regions than in the east. For the central and western regions where commercial financial support is not strong, policy-based finance plays an important role in promoting the upgrading of industrial structure, regional economic development and narrowing the regional economic gap in China. Therefore, the state should continue to increase the policy and financial support to the western region, further improve the level of infrastructure in the western region, and boost the enthusiasm of domestic and foreign funds to invest in the western region. In addition, income as a key factor affecting consumption, the state should reform the income distribution system, fiscal taxation system, transfer payment system, pension, medical security and other aspects, effectively improve the income level of residents in the western region, reduce the uncertainty of residents' income, and enhance the willingness of residents to spend. We will enhance the driving role of consumption in the up- 
grading of industrial structure and the sustainable growth of regional economy. Third, all regions should evaluate the comparative advantages of industries, adjust the industrial structure, and focus on the development of industries with comparative advantages. In particular, it is necessary to increase support for characteristic industries. Under the background of China's urbanization construction, economic new normal and supply-side structural reform, it is necessary to give play to the role of policy-based financial institutions in regional infrastructure construction, characteristic industry cultivation and industrial structure adjustment, and foster new economic growth points in the region. Under the condition of limited regional resources, the enterprises with high consumption and low yield should be eliminated, the enterprises with good efficiency should be developed, and the utilization rate of resources should be improved. In other words, we need to give full play to the important role of policy-based finance in providing financial support in the process of overcapacity reduction and structural adjustment.

\section{Conclusion}

Based on theoretical analysis and policy perspective, this paper studies the impact of regional financialization on industrial structure upgrading. The results show that the improvement of regional financialization level has a significant positive effect on the transformation and upgrading of local industrial structure. On the one hand, through capital formation and capital orientation mechanism, the financial system increases the credit investment to labor-intensive and technology-intensive industries, thus promoting the optimization of industrial structure. On the other hand, the financial system plays the functions of credit catalysis and risk management. While avoiding financial risks, it absorbs more funds to invest in industrial development through the promotion of credit expansion to economic growth, so as to improve the efficiency of industrial capital formation and promote the upgrading of industrial structure. Moreover, the contribution rate of fiscal finance in promoting industrial structure optimization in the western region is higher than that in the central and eastern regions. This shows that in both promoting the adjustment of industrial structure and industrial structure to promote regional coordination, finance can play an important role, deepen the reform of the industrial structure adjustment, the supply side in China completed a key period, fiscal and financial policy support guide function, to realize the adjustment of industrial structure reform plays an important role in promoting, The government should increase efforts to support characteristic industries and increase financial and financial investment, so as to improve the financial and financial system to promote the sustainable and healthy development of China's economy.

\section{Conflicts of Interest}

The author declares no conflicts of interest. 


\section{References}

[1] Li, F.C. (2012) The Industrial Upgrading Effect of Foreign Direct Investment in Home Country-An Empirical Study from China's Provincial Panel. International Trade Issues, 2012, 124-134.

[2] Zhang, Q. (2016) Research on the Relationship between the Secondary Industry Structure Adjustment and the Linkage Development of Science, Technology and Finance. Scientific Management Research, 34, 109-112.

[3] Chen, Y.N. and Bao, H.N. (2017) Empirical Analysis of the Impact of Technological Finance Development on Industrial Structure Upgrading. Statistics and Decision, 2017, 170-173.

[4] Wang, Z. (2014) Analysis on the Mechanism of Financial Support for Industrial Structure Adjustment: Based on the Dimension of Total Volume, Efficiency and Structure. Prices in China, 2014, 40-43.

[5] Xu, Y.S. and Qi, L. (2017) Regional Financialization, Local Government Behavior and Industrial Structure Upgrading. Journal of Guizhou University of Finance and Economics, 2017, 19-31.

[6] Bai, Q.X. (2005) Reflections on the Theory and Practice of Policy Finance at Home and Alive. Journal of Guangdong University of Finance, 2005, 3-10.

[7] He, Z.X. and Qu, R.X. (2015) Agricultural Policy-Based Financial Supply and Rural Financial Inhibition: Empirical Evidence from 147 Counties. Financial Research, 2015, 148-159.

[8] Fu, L.H. (2010) An Empirical Study on the Relationship between Industrial Structure Upgrade and Economic Growth in China. Statistical Research, 2010, 79-81.

[9] Ji, Z.H. (2013) Research on Regional Differences of Loan to Deposit Ratio-Based on the Data of Commercial Banks' Branches. Financial Research, 2013, 12-31.

[10] Zhang, H.J. (2016) Research on the Impact of the Cancellation of Deposit Loan Ratio on the Operating Performance of China's Commercial Banks. Journal of Changzhou University (Social Science Edition), 17, 73-79. (In Chinese)

[11] Xu, M. and Zhang, X.L. (2015) GSP Financial Development and Industrial Structure Adjustment. Business Research, 2015, 79-85. (In Chinese)

[12] Levine, R. (2005) Chapter 12 Finance and Growth: Theory and Evidence. In: Aghion, P. and Durlauf, S.N., Eds., Handbook of Economic Growth, Volume 1, Part A, 865-934. https://www.sciencedirect.com/science/article/abs/pii/S1574068405010129 